\title{
SUSTAINABLE CITIES INDICES IN MODERN ARCHITECTURE: A COMPARATIVE STUDY IN UAE
}

\author{
IMAN ABDEL SHAHID IBRAHIM \\ Interior Architecture Design, University of Sharjah, UAE
}

\begin{abstract}
The Global Footprint Network reported, in the Living Planet Report 2006, that the United Arab Emirates was the country with the largest per capita ecological footprint in the world, where the UAE government started the journey towards an ecological footprint to ensure a sustainable future by measuring and understanding the impact of the country's development. Today, the UAE ecological footprint initiative stands as an exemplary model for nations in using the ecological footprint to measure consumption patterns. Sustainable cities' vision was one of the key elements pushing the community to live green, starting in 2008 with the first sustainable city in Arab world, Masdar city in Abu Dhabi, followed by the second sustainable city in Dubai, started in 2013. The city is smaller, a manageably sized community that adopted new clean technologies getting optimum benefit of the sunny weather by using photovoltaic panels as a main energy source. There is no doubt that the sustainable city seems to be a utopian city in concept, but eventually it seems to be the only solution for raising communities with a sustainable social life that will change traditions and cultures towards a more ecological footprint. Dubai Sustainable City is a successful model that achieved a sustainable community with about 2,700 people currently live in the city, with different nationalities and mixed cultures that all aspired to an ecological environment and a future sustainable generation. Followed by Sharjah Sustainable City 2020, a new sustainable city in a different local community, adopted the same sustainability aspects. More modifications on design were offered to satisfy the local community social needs and to raise the acceptance levels for ecological footprint. The study will analyze the sustainable city concept rising in Arab countries with a deep investigation for Dubai and Sharjah sustainable cities and how far different cultures affect community acceptance for sustainability as a lifestyle.
\end{abstract}

Keywords: sustainable cities, sustainability circles, Dubai Sustainable City, Sharjah Sustainable City.

\section{INTRODUCTION}

Humanity is causing stress to the planet. People are unconsciously consuming the earth's resources with little restraint in their lives to the point where their demands on nature have exceeded the earth's capacity. In fact, due to global growth, consumption is constantly increasing, and the resources are becoming a deficit. Countries that fail to balance the demands with the resources will suffer from a high ecological footprint. This is when nations should aim for sustainability, including the United Arab Emirates (UAE).

In 2006, the World Wildlife Fund (WWF) reported the UAE as the world's highest per capita ecological footprint [1]. More than " 4.5 earths" would be needed to comply to all population demands if the consumption rate of other countries was as high as the UAE [2]. Since then, the UAE government started the journey towards an ecological footprint that would ensure a sustainable future. Moreover, the focus on sustainability became a task that requires sufficient efforts and continuous commitments.

Carbon footprint was the main reason to record the highest UAE ecological footprint [3]. This is due to the dramatic increase of energy consumption and carbon emissions released by the high population in the UAE. Therefore, the government took solid steps towards managing the ecological footprint by establishing initiatives and campaigns to raise awareness and adjust people's unsustainable consumption patterns. Meanwhile, the government investments in cleaner energy and interest in sustainable development has grown. The result of the government actions has set the UAE to be the third country in the world to significantly manage the 
ecological footprint, after Switzerland and Japan [4]. Thankfully, in 2015, the devotion of the government has caused a steep drop in the ecological footprint as the ministry of Environment and Water in UAE has reported [5].

In the last few years, the green revolution has dug its roots towards a sustainable future. In fact, the UAE vision 2021 is to consume $50 \%$ of clean energy in the country [6]. The vision also focuses on affording high standards of living and a healthy life by ensuring sustainability development is enriched for all individuals. Therefore, the UAE is implementing green strategies and approaches that support sustainability. For example, clean and renewable energy projects in Dubai were adopted by Dubai Electricity and Water Authority (DEWA). This includes the Mohammad Bin Rashid Al Maktoum Solar Park that is expected to produce 5,000 MW by 2030 [7]. Similarly, the Estidama project was executed by Abu-Dhabi in 2009 to become the first organic sustainability frameworks in the Middle East [6].

\section{SUSTAINABILITY AND SUSTAINABLE DEVELOPMENT IN ARAB COUNTRIES}

Sustainability is an appealing term for all countries that aim to keep their delicate ecosystem in balance. "Sustainability" and "sustainability developments" are two terms that one can get confused easily. Therefore, the United Nations Educational, Scientific and Cultural Organization (UNESCO) defined sustainability as a "long-term goal" and defined sustainability development as "the process to achieve that goal of sustainability" [8]. However, Galal Ahmed [8] claims that "sustainability" and "sustainability development" are two terms that can be used interchangeably.

To deliberate sustainability development, the environmental, social, and economic elements should be maintained evenly [9]. Azar and Raouf [10] claimed that sustainability is the solution to all the current environmental, economic, and social imbalances facing the GCC countries. The rapid increase of population and economic growth resulted in high unsustainable consumption rates. As a result, all the GCC countries consumption rates were highly ranked according to the International Energy Agency (IEA) report, including the UAE (9th) [11]. Accordingly, the GCC countries adopted the Sustainable Development Goals (SDGs) to achieve a sustainable future.

Urban growth is expected to be increasing in developing countries that face social, economic, and environmental challenges. Therefore, the UN agenda suggested shifting towards achieving sustainable cities. El-Kholei and Yassine [12] defined "sustainable city" as a "metropolis that can balance economic growth with social equity while protecting natural resources from irresponsible use and waste". However, Bithas and Christofakis [13] believes that "environmental sustainability is the key driver that allows the existence for other aspects of sustainability".

Arab cities face many sustainable challenges: rapid urbanization, slow economic growth, unemployment, shortage of energy and basic services, insufficient infrastructure, and environmental pollution [14]. Issa and Al Abbar [15] supports that the middle east countries are facing challenges to become eco-friendly and implement sustainability.

Green building codes are frameworks adopting sustainability; Qatar and Lebanon are examples of countries that used this tool to maintain sustainability. The Qatar Global Sustainability Assessment System (GSAS) was one of the first green building rating systems in the middle east to focuses on all the sustainability criteria [15]. 


\subsection{Evaluating sustainable cities}

Rating systems are used as an indicator to evaluate the sustainability performance of the real estate industry. The aim of these systems is to promote sustainability practices and to allow designers to assess the compliance of their projects to sustainability. Several rating systems were published in the real estate industry. For example, the Leadership in Energy and Environmental Design (LEED) system is an international system that target the energy and water efficiency, reduction of $\mathrm{CO}_{2}$ emissions and the conservation of resources. Among the 140 countries listed, the UAE was the only Middle Eastern country that implemented the LEED system [18]. Also, BREEAM rating system is considered the oldest sustainability rating method. Green Star, CASBEE, and Estidama are also rating systems that are widely and globally used [19], in addition to the rising rating systems in the Middle Eastern countries as shown in Table 1.

Table 1: Successful Green Building codes in the Middle Eastern countries [18].

\begin{tabular}{|l|l|l|}
\hline \multicolumn{3}{|c|}{ Summary of the regional Green Building rating systems } \\
\hline $\begin{array}{l}\text { Sustainable rating } \\
\text { system }\end{array}$ & $\begin{array}{l}\text { Managing } \\
\text { organization }\end{array}$ & Area of focus \\
\hline $\begin{array}{l}\text { The Global } \\
\text { Sustainability } \\
\begin{array}{l}\text { Assessment } \\
\text { System (GSAS), } \\
\text { Qatar. }\end{array}\end{array}$ & $\begin{array}{l}\text { Gulf } \\
\text { Organisation for } \\
\text { Research and } \\
\text { Development } \\
\text { GORD) }\end{array}$ & $\begin{array}{l}\text { The goal of GSAS is to reduce ecological impact, conserve } \\
\text { water an energy, reduce landfill waste and create a } \\
\text { sustainable environment. The 8 categories to assess the } \\
\text { performance: Energy, Water, Indoor Environment, Cultural } \\
\text { \& Economic value, Site, Urban Connectivity, Material, and } \\
\text { Management \& Operation. }\end{array}$ \\
\hline $\begin{array}{l}\text { ARZ Green } \\
\text { Building Rating } \\
\text { System, Lebanon. }\end{array}$ & $\begin{array}{l}\text { The Lebanese } \\
\text { Green Building } \\
\text { Council (LGBC) }\end{array}$ & $\begin{array}{l}\text { The nine modules of ARZ system that adopt promotes the } \\
\text { achievement of sustainably: Energy Performance, Thermal } \\
\text { Energy, Electrical Energy, Building Envelope, Materials, } \\
\text { Indoor Air Quality, Water Conservation, and Operations and } \\
\text { Management. }\end{array}$ \\
\hline $\begin{array}{l}\text { Pearl Rating } \\
\text { System } \\
\text { (Estidama), UAE. }\end{array}$ & $\begin{array}{l}\text { Abu Dhabi } \\
\text { Urban Planning } \\
\text { Council }\end{array}$ & $\begin{array}{l}\text { The system consists of 7 components to assess the } \\
\text { performance: Integrated Development Process, Natural } \\
\text { systems, Liveable communities, Precious water, Resourceful } \\
\text { energy, Stewarding Materials, Innovation. }\end{array}$ \\
\hline
\end{tabular}

Rating systems could rate buildings variously [20]. For example, a UK building could be rated differently if using LEED and Green Star rating systems instead of the UK BREEAM system. The rating systems have the same aspects, but they all focus exclusively on environmental aspects and fail to consider social and economic aspects [21], [22]. Accordingly, Middle Eastern countries adopt international rating systems while developing their own rating systems to match their vision, market needs, and unique environment [18].

\subsection{Sustainable cities in UAE}

The UAE mastered the effective implementation of the green building codes to the extent that the Pearl Rating System was launched. It ensures that all phases of any project is addressing the sustainability concept [24]. Fortunately, urban spaces and building designs in the UAE in particular have contributed towards sustainability [25]. Accordingly, the UAE was ranked the ninth among the top 10 countries with the biggest energy-efficient development outside the United States [15]. 
Dubai aims by 2050 to achieve $75 \%$ clean energy. Therefore, one of the interesting ideas by the UAE was to design a sustainable community in the desert; Dubai Sustainable City [25]. This city relies on water and waste recycling and energy production that outweighs the consumption [26]. Nadali et al. [27] suggested the improvement of social and environmental dimensions to enhance the efficient implementation of sustainability. Recommendations were stated to improve the social and environmental dimensions in terms of improving equity, increasing landscapes, raising awareness of water consumption practices, etc.

In 2008, Abu Dhabi launched Masdar city as the most sustainable urban city in the world. Masdar city is a pioneer in sustainability practices where all buildings use $40 \%$ less energy compared to normal buildings. The city aims to be the first zero carbon emission and zero waste city in the next few decades [28].

\section{NEW VISION FOR SUSTAINABILITY CIRCLES}

Blum and Grant [29] demonstrate that sustainable development is achieving the balance of the three sustainability pillars, economic, social, and environmental, while considering the urban development measures. However, this approach seems to be very broad and does not involve all domains of urban development.

James et al. [30] was the first who aimed to cover all the domains of sustainability. Basically, the circle of sustainability takes the approach of the three pillars of sustainability and generalize a framework that provides more than high-sounding words. It is an integrated approach to understand and assess cities in global and local context. The environmental pillar was substituted by the ecological domain. As illustrated in Fig. 1, James et al. [30] refuses to prioritize economic and treat it as a domain outside of social life as he states: "Economics is important, but when treated as primary it threatens to rip the heart out of prior cultural and ecological ways of life". Accordingly, the four domains were introduced: economics ecology, politics, and culture.

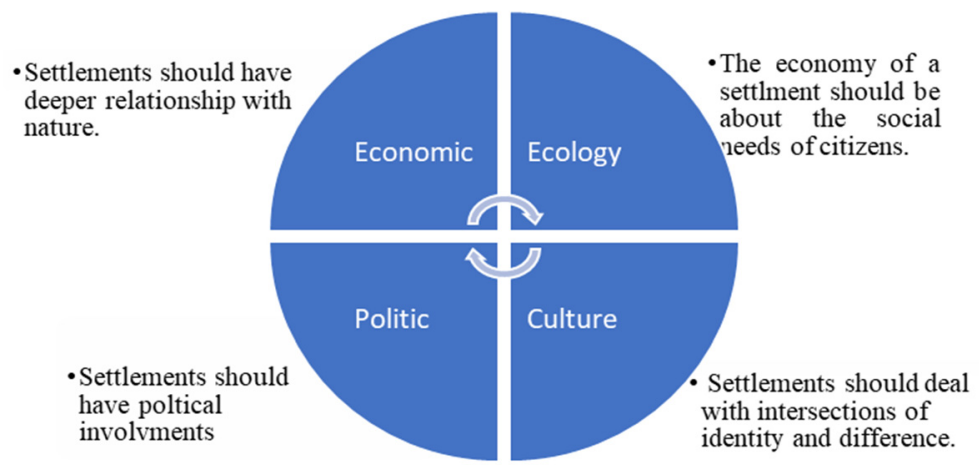

Figure 1: Principles of circles of sustainability [30], [31].

\section{UN-HABITAT CONCEPTUAL EVALUATION FOR SUSTAINABLE CITIES}

As the world is changing, people are shifting from rural areas to cities and are relocating in other countries. Hence, the quick economic growth and immigration evolved. Simultaneously, there was a lack of housing, overconsumption of natural resources, poverty, inequality, pollution, and instabilities in social and cultural values [32]. Consequently, these urbanization challenges should have been addressed by refining the urban planning of sustainable neighborhoods and cities. Therefore, the UN-habitat developed a new urban planning strategy 
to overcome these challenges [33]. The UN-habitat recommended five principles to support the urban future development and to build a sustainable relationship between urban citizens and urban spaces [33]. The five principles are:

1. Adequate space for streets and an efficient street network. The street network should engage at least $30 \%$ of the land and at least $18 \mathrm{~km}$ of street length per $\mathrm{km}^{2}$. Principle one aims to be pedestrian- and cyclist-friendly where lands allocated for parking are reduced to $20 \%-30 \%$. It also adjusts street networks (i.e. street hierarchy, arterial routes and local streets) to balance between streets and other land uses.

2. High density. The concentration of people and their activities. This is where the allocation of residents should be at least 15,000 people per $\mathrm{km}^{2}$. Principle two focuses on global population explosion and rapid urbanization. It includes efficient land use to accommodate more urbans, provide social equity, increase energy efficiency, and reduce pollution.

3. Mixed land-use. At least $40 \%$ of floor space is for economic use for neighborhood. Principle three provides local jobs, promotes the local economy, minimizes car dependency, and supports mixed economies. It includes reforming the city to balance the allocation economic use, residential use, public services, and other land use.

4. Social mix. Principle four is "socio-spatial concept" that aims to ensure urban equity in terms of housing and promote the interaction between social classes in a community; $20 \%$ to $50 \%$ of the residential floor should be for low-cost housing and each tenure type should not exceed $50 \%$ of the total.

5. Limited land-use specialization. Principle five focuses on the land-use aspects. It aims to limit or adjust the zoning policies. Zoning is a land use planning device used by local governments and urban planners in countries. The use of blocks and neighborhood should be minimized, and single blocks should cover at least $10 \%$ of the neighborhood [33].

\subsection{Dubai Sustainable City}

Sustainable City in Dubai is the first sustainable city in the UAE that was launched in 2015. Dubai's Sustainable City urban planners aimed to embrace a sustainable urban design setting, making it the first net zero service in Dubai. The strategy of the city is based on the three pillars of sustainability. The social sustainability includes the promotion of high standard

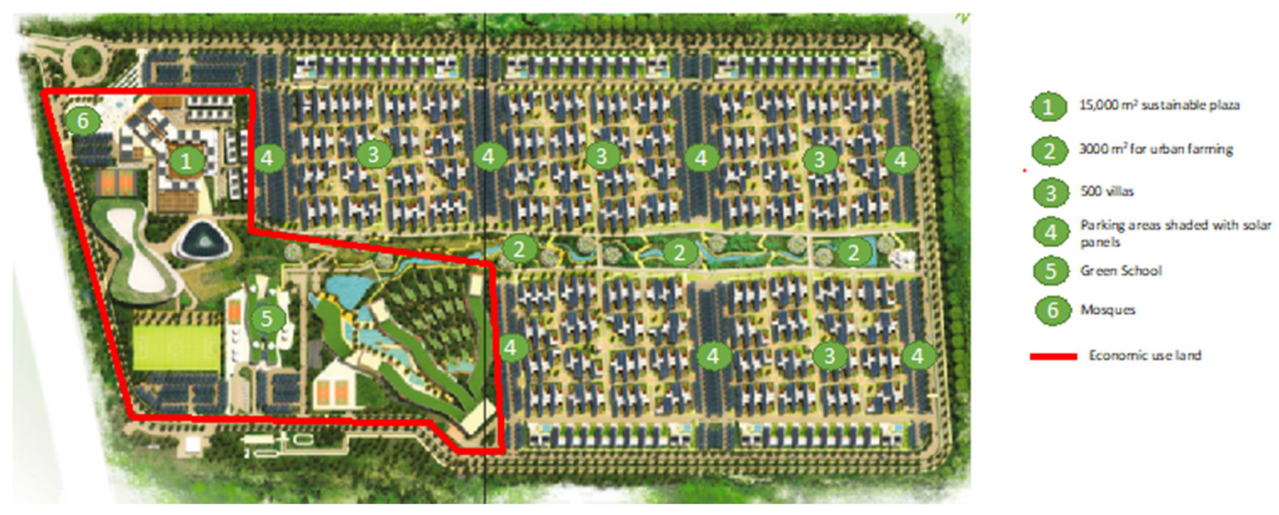

Figure 2: The master plan of Dubai Sustainable City and land use [35]. 


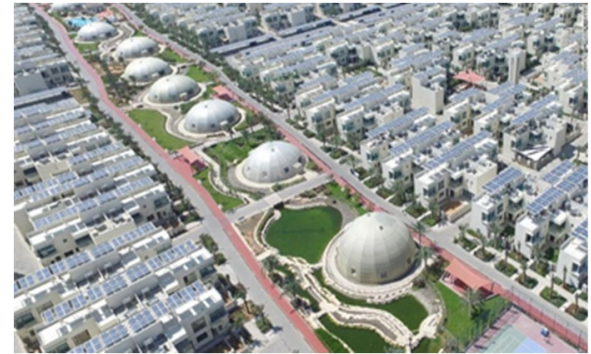

(a)

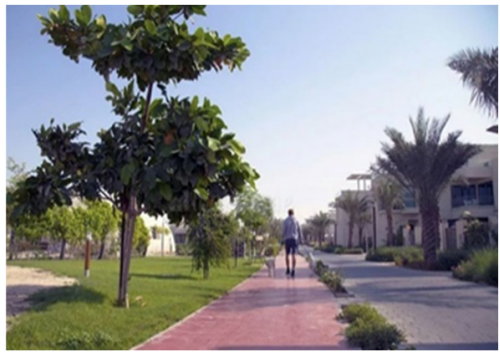

(b)

Figure 3: The street network of Dubai Sustainable City. (a) Different street network; (b) Standard walking paths [35].

of living and affording community outreach programs. Changing the orientation of blocks and adding multistore zone beside detached and semi-detached villas will improve the social interaction and social sustainability [34]. The environmental sustainability includes the maintenance of passive and active design strategies. The economic sustainability focuses on taking advantage of operational efficiencies and afford the savings to the urbans in the city as shown in Fig. 2.

El-Khateeb [36] presents a clear analysis about the implementation of principles of the sustainable neighborhood design which UN-habitat developed.

- Principle one is fully implemented. The street network in Dubai Sustainable City exceeded $30 \%$ of the land, particularly $45 \%$ as shown in Fig. 3.

- Principle two was not successfully achieved due to the low density of people; 6,000 people per km2. Low-population density and family-friendly community development with facilitating the nurturing of community-conscious neighborhoods, allowing all members of the community to organize and participate in the activities within the city. The range of facilities made available in the city will meet the different personal and communal needs of its residents, not only set on providing residential space but it is also envisaged to have the capacity to provide everyone the opportunity to study, work and enjoy his/her leisure time where Fig. 4 illustrates different afforded facilities.

- Principle three is mixed land use where $45 \%$ of the floor space of the city was allocated for economical use (e.g. mall, hospital, school, etc.).

- Principle four was not fully implemented. Different house price ranges were afforded to accommodate different social classes income and residential tenure was $50 \%$ of the total as certified in the principle. However, only $10 \%$ of the residential floor was for low-cost housing. Based on residents' surveys and interviews as shown in Fig. 5, residents most often emphasized that they were attracted by the sustainability ethos and goals of the city. Although most share a strong personal desire to live sustainably, residents were also drawn to the city by the physical design of house and community, quality of life and safety, value for money, location, and lower energy bills due to solar photovoltaic. It is noticed that a high portion of residents considered the pricing of villas and houses as a major reason to live in a sustainable city.

- Principle five was executed successfully. Single use of blocks or neighborhoods were limited. The single blocks in sustainable Dubai city were about $40 \%$, which means $30 \%$ more than what principle five stated. 
1 Entrances

2 Buer Zone (Green Belt)

3 Residential Villas

4 Organic Farm

5 Community Centre

6 Eco-resort

7 Community Club

8 Equestrian Centre

9 Green School

10 Planetarium

11 Sustainability Centre

12 Mosques

13 Solar Covered Parking

14 Ring Road

15 Utilities

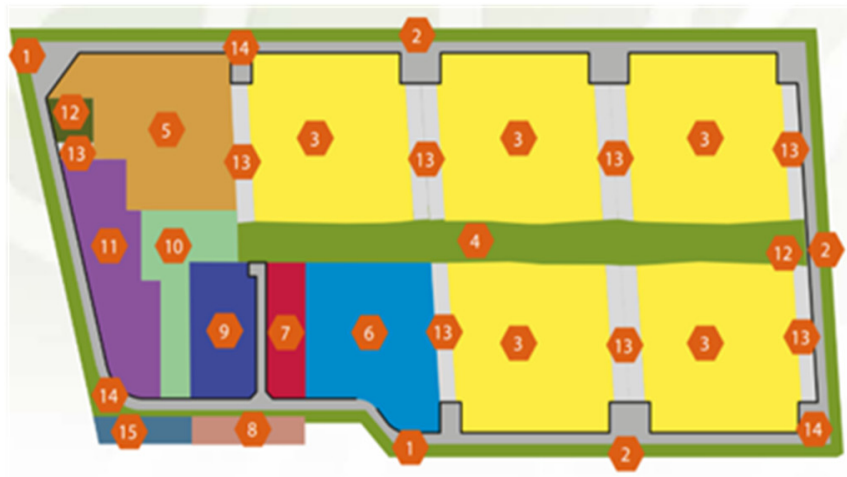

Figure 4: Mixed-land use and community facilities [35].

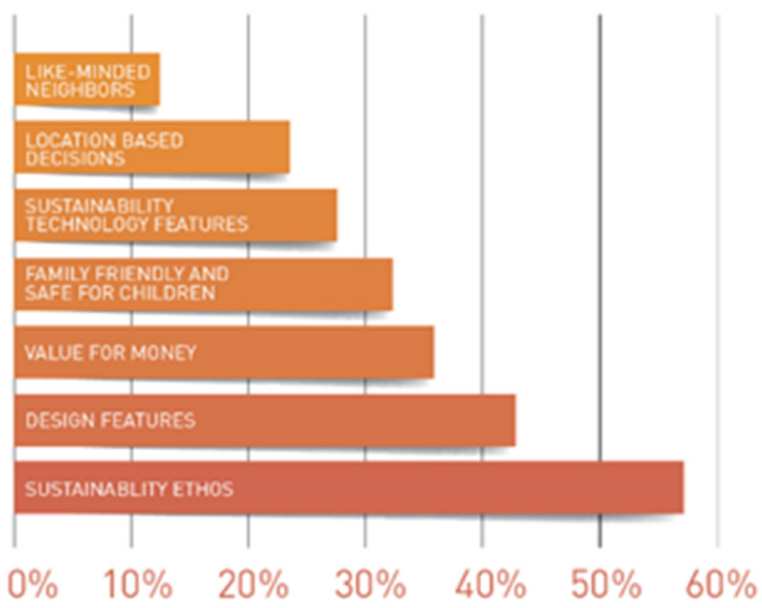

Figure 5: Reasons why residents chose to live in the city $(\%$ of residents mentioning each reason [37].

Generally, the city implemented most of the principles; however, it did not meet the target for principle two where a mixed high density was expected in Dubai's 5,000,000 square feet city, and the target for principle four where the low-cost housing area in Dubai was not in the range $20 \%-50 \%$ as principle four certified, at only $10 \%$.

\subsection{Sharjah Sustainable City (SSC)}

Diamond Developers have rooted their steps in embracing all aspects of sustainable development. The Dubai Sustainable City was one of their successfully implemented projects in the nation. As a second step, Diamond Developers decided to execute another sustainable city in Sharjah holding similar vision and similar master plan. However, Sharjah has a different local community where modifications should be introduced to the master plan as shown in Fig. 6. 


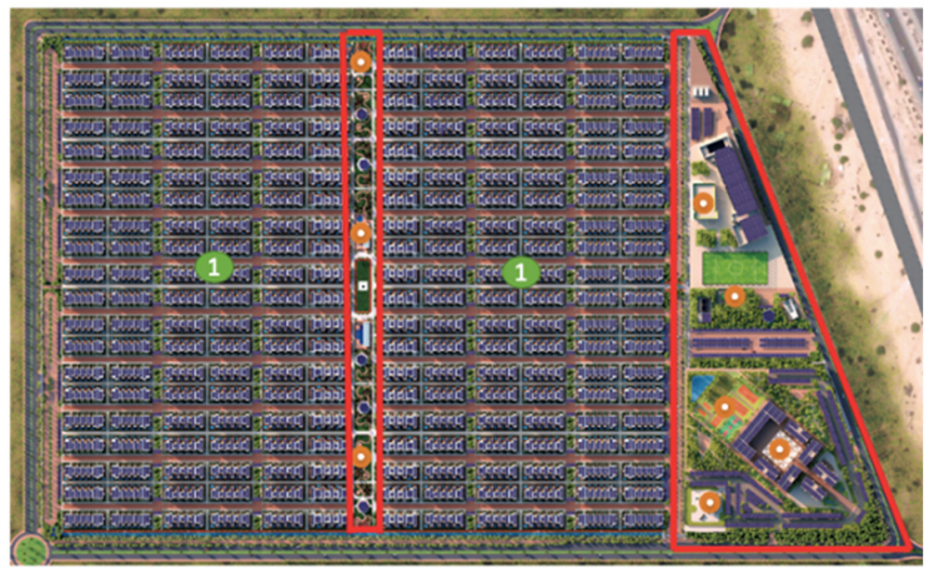

1. 498 Villas and 89 Apartments and studios - Mixed-land use

Figure 6: Master Plan of the SSC [37].

Sharjah Sustainable City is the first net zero community in Sharjah. It relies $100 \%$ on solar power and $100 \%$ on recycling water and waste. It also encourages walkability and the use of clean mobility. Similar to Dubai Sustainable City, Sharjah Sustainable City obeys the three pillars of sustainability. The environmental sustainability involves waste recycling, urban farms, reuse of water for irrigation, etc. The social sustainability involves health clinics, schools, gyms, and other community programs. The economic sustainability is maintained by green economy and includes the $100 \%$ savings on electricity bills, $50 \%$ savings on water bills, and zero service charges for the first 5 years [38].

Because Sharjah Sustainable City is being constructed by the same developer of the Dubai Sustainable City (Diamond Developer), it is assumed that it will accommodate the same number of residents and residential buildings (apartments and villas) The economic-use land area and network streets will be launched to meet the UN-habitat five principles.

- Principle one. The design of the Sharjah Sustainable City will involve pedestrianfriendly walkways to attract cyclists and pedestrians. The land will allocate roads for low carbon transportation and sufficient parking areas for residents. These features fulfil the aims of principle one, as it is observed that the total street area is $30 \%$ as shown in Fig. 7.

- Principle two. The anticipated residential population is about 2,700 people on a land of $670,000 \mathrm{~m}^{2}$ [40]. In other words, about 4,000 people will be located per $\mathrm{km}^{2}$. This means that SSC might suffer a mixed low density and principle two will not implemented.

- Principle three. As shown in the SSC master plan, it can be visually assumed that the economic-use land is about $20 \%-30 \%$ which is not achieving the aim of principle three. Also, it is visually observed that the total residential floor area in SCC is larger than Dubai's Sustainable City by about $30 \%$ as shown in Fig. 8 .

- Principle four. The design city covers three different units: 450 townhouses, 50 detached villas, and 89 studios [37]. SCC have competitive and affordable prices for all the units. This means different price ranges which is the purpose of principle four. The price range are cheaper than DSC by approximately $40 \%$ [42]. SSC has a different nature culture, where locals are of diverse nationality, there is more green open space, and larger front 
yards are afforded. Therefore, it is assumed that tenure and housing residential floor areas $(20 \%$ and $80 \%)$ are more than the Dubai Sustainable City.

- Principle five. The single use of blocks or neighborhoods were $40 \%$ in Dubai Sustainable City. Hence, SSC is expected to have a similar percentage of single use of blocks. A summary of UN-habitat principles is shown in Fig. 9.

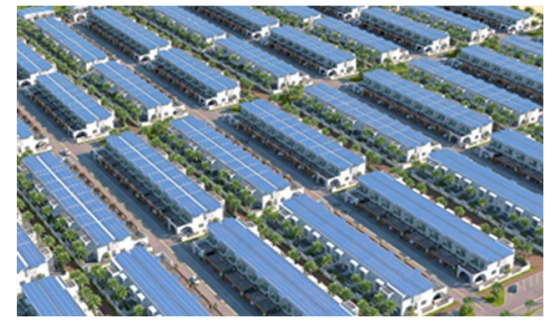

(a)

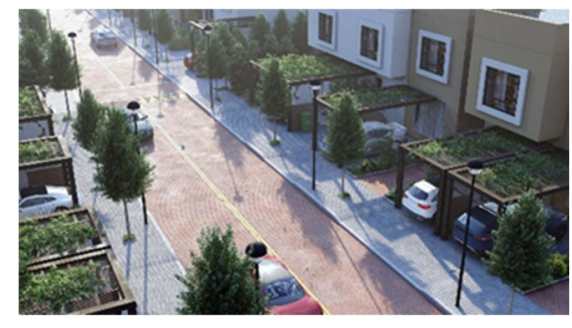

(b)

Figure 7: The street network of SSC. (a) Street network; (b) Walking paths [39].

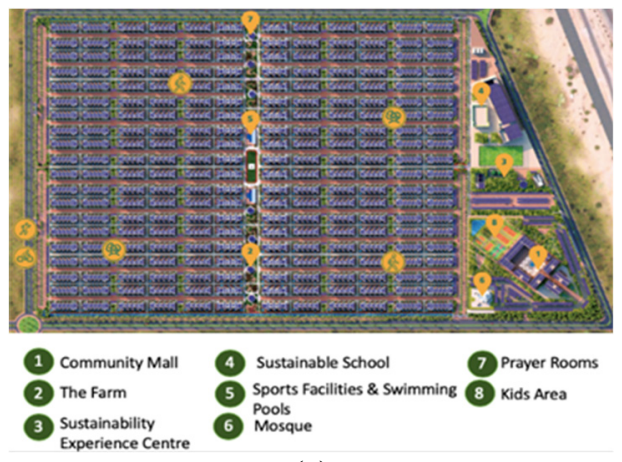

(a)

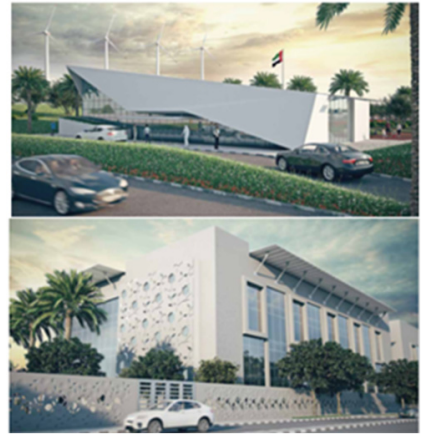

(b)

Figure 8: (a) Mixed-land use in SCC; (b) Community facilities [39], [41].

\section{CONCLUSION}

In line with His Highness, Sheikh Mohammed Bin Rashid's initiative towards a "green economy for sustainable development", Diamond Developers planned the Dubai Sustainable City project. It embraces a sustainable urban design setting which clearly has demonstrated the three sustainable aspects. After the success of this project, Diamond Developers continue to plan another sustainable city in Sharjah: the SSC. The Sharjah Sustainable City is still under construction; however, it is expected to involve the same features and sustainability aspects. In order to evaluate to what extent those two cities have achieved in terms of sustainable neighborhood development, the five UN-habitat principles are used.

Sharjah Sustainable City has adjusted the master plan to involve more green and open space areas in which locals are the diverse nationality who are resident. Therefore, SSC complies principle four in terms of larger affordable housing residential floor areas. In 


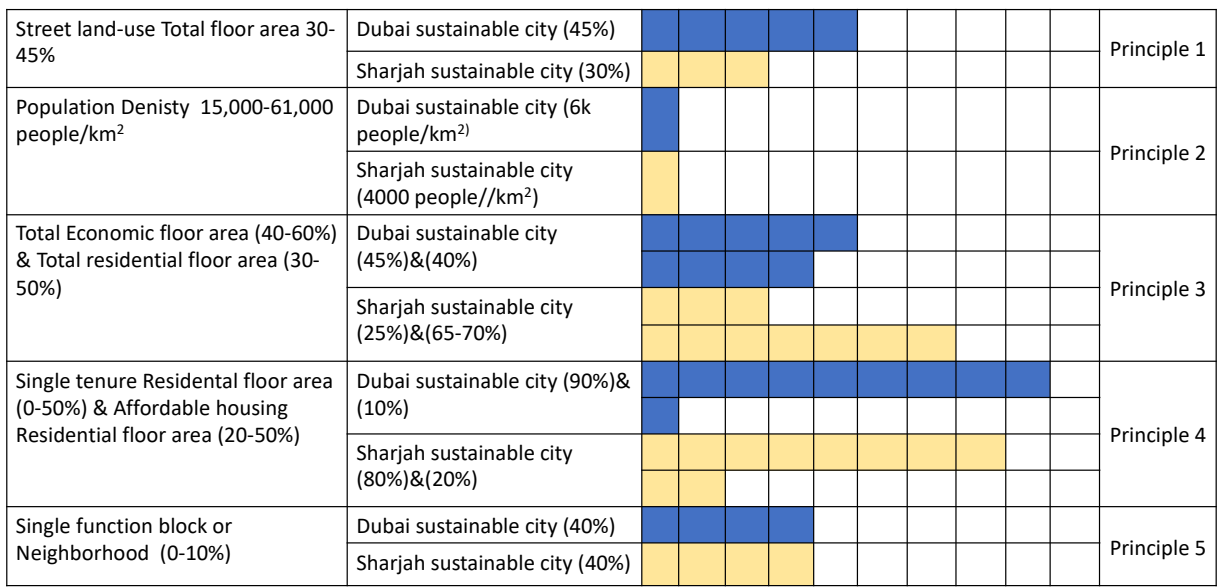

Figure 9: Application of the UN principles on the sustainable cities. (Source: Authors.)

addition, both cities suffer a mixed-low density which means the target of principle two is not achieved. It is true that SSC is not yet fully executed; however, the anticipated population was stated in the SSC reports (2019). Principles five and one are fully implemented for both DSC and SSC. Regarding principle three, SSC is visually assumed to have a $25 \%$ economic floor area which is a lower percentage than the principle target by $20 \%$. Overall, the key success to achieve a future sustainable neighborhood is implementing the three pillars of sustainability in addition to the five UN-habitat principles.

\section{REFERENCES}

[1] Fox News, United Arab Emirates has highest per capita "ecological footprint" 2007. https://www.foxnews.com/story/report-united-arab-emirates-has-highest-per-capitaecological-footprint. Accessed on: 15 Jul. 2020.

[2] Al Sammani, A.M., The Sustainable Development of Local Housing Units in UAE, 2011.

[3] Abdullatif, L. \& Alam, T., The UAE Ecological Footprint Initiative Summary Report 2007-2010, 2011.

[4] United Arab Emirates, Global Footprint Network, 2015.

[5] The National Staff, UAE ecological footprint has dropped 2015. https://www.thenational.ae/uae/environment/uae-ecological-footprint-has-dropped1.79232. Accessed on: 15 Jul. 2020.

[6] MyBayut, Sustainable developments in the UAE: Top projects \& initiatives.

[7] Al Tayer, S.M., UAE powers towards a sustainable future, Gulf News, 2018. https://gulfnews.com/opinion/op-eds/uae-powers-towards-a-sustainable-future1.2160141. Accessed on: 15 Jul. 2020.

[8] Galal Ahmed, K., Evaluation of social and cultural sustainability in typical public house models in Al Ain, UAE. International Journal of Sustainable Development and Planning, 6(1), pp. 49-80, 2011. DOI: 10.2495/SDP-V6-N1-49-80.

[9] Jenks, M. \& Jones, C., Chapter 1: Issues and concepts. Dimensions of the Sustainable City, p. 21, 2010.

[10] Azar, E. \& Raouf, M.A., Sustainability in the Gulf: Challenges and Opportunities, Routledge, 2018. 
[11] IEA, Global energy efficiency market: "An invisible powerhouse" worth at least USD 310 billion per year, 2014. www.iea.org/newsroomandevents/ pressreleases/2014/october/global-energy-efficiency-market-an-invisiblepowerhouse-at-least-usd-310byr.html. Accessed on: 15 Jul. 2020.

[12] Ahmed, G.Y. \& El-Kholei, O., The mirage of smart sustainable cities in the Arab region. Open House International, 44, 2019.

[13] Bithas, K.P. \& Christofakis, M., Environmentally sustainable cities: Critical review and operational conditions. Sustainable Development, 14(3), pp. 177-189, 2006. DOI: $10.1002 / \mathrm{sd} .262$.

[14] Hamza, K., Smart city implementation framework for developing countries: The case of Egypt. Smarter as the New Urban Agenda, pp. 171-187, 2016.

[15] Issa, N. \& Al Abbar, S., Sustainability in the Middle East: Achievements and challenges. International Journal of Sustainable Building Technology and Urban Development, 6(1), pp. 34-38, 2015. DOI: 10.1080/2093761X.2015.1006709.

[16] Bostock, B., Everything we know about Neom, a "mega-city" project in Saudi Arabia with plans for flying cars and robot dinosaurs, Market Business Insider, 2019. https://markets.businessinsider.com/news/stocks/neom-what-we-know-saudi-arabia500bn-mega-city-2019-9-1028545234\#. Accessed on: 16 Jul. 2020.

[17] NEOM, An Accelerator of human progress, 2020.

[18] Shahid Ibrahim, I.A., Green architecture challenges in the Middle East within different rating systems. Energy Procedia, 115, pp. 344-352, 2017. DOI: 10.1016/j.egypro.2017.05.031.

[19] Rogmans, T. \& Ghunaim, M., A framework for evaluating sustainability indicators in the real estate industry. Ecological Indicators, 66, pp. 603-611, 2016. DOI: 10.1016/j.ecolind.2016.01.058.

[20] Reed, R., Bilos, A., Wilkinson, S. \& Schulte, K.W., International comparison of sustainable rating tools. Journal of Sustainable Real Estate, 1(1), pp. 1-22, 2009.

[21] Reith, A. \& Orova, M., Do green neighbourhood ratings cover sustainability? Ecological Indicators, 48, pp. 660-672, 2015.

[22] Berardi, U., Beyond sustainability assessment systems: upgrading topics by enlarging the scale of assessment. International Journal of Sustainable Building Technology and Urban Development, 2(4), pp. 276-282, 2011.

[23] KNPC, MAB Administration Building is awarded Green Building Silver Certificate, 2018.

[24] Abu Dhabi Urban Planning Council, Estidama Pearl Building rating system: Design \& construction, 2010.

[25] El-Bana, N., Selim, S.H. \& Taleb, H., Optimising sustainability at an urban level: A case study of Dubai Sustainable City. Sustainable Development Planning VII, 1, pp. 985-995, 2015. DOI: 10.2495/sdp150831.

[26] Kunzig, R., The world's most improbable green city, National Geographic, 2017. https://www.nationalgeographic.com/environment/urban-expeditions/green-

buildings/dubai-ecological-footprint-sustainable-urban-city/. Accessed on: $16 \mathrm{Jul}$. 2020.

[27] Nadali, P., Thomas, R.M. \& Taleb, H., Rethinking and redesigning sustainability in Dubai's Sustainable City. Sustainable Development Planning, 193, 2015. DOI: 10.2495/SDP150841.

[28] Bakr, A. \& Lewis, B., Finding a balance: UAE eyes sustainable growth, Reuters, 2010. https://www.reuters.com/article/us-emirates-sustainabilityidUSTRE69C5F620101013. Accessed on: 15 Jul. 2020. 
[29] Blum, A. \& Grant, M., Sustainable neighbourhoods: Assessment tools for renovation and development. Journal of International Research Publications: Ecology and Safety, 1, pp. 35-52, 2006.

[30] James, P. et al., Urban Sustainability in Theory and Practice Circles of Sustainability, 2013.

[31] Circles of Sustainability, Principles.

https://www.circlesofsustainability.org/principles/. Accessed on: 18 Jul. 2020.

[32] Dehghanmongabadi, A., Hoşkara, S.O. \& Shirkhanloo, N., Introduction to achieve sustainable neighborhoods. International Journal of Arts and Commerce, 3(19297106), pp. 16-26, 2014.

[33] UN Habitat, A new strategy of sustainable neighbourhood planning: Five Principles, Discussion Note 3 - Urban Planning, p. 8, 2015.

[34] El-Bana, N., Selim, S.E. \& Taleb, H., Optimising sustainability at an urban level: A case study of Dubai Sustainable City. Sustainable Development and Urban Planning, 2015.

[35] Diamond Developers, The sustainable city: A project by Diamond Developers.

[36] El-Khateeb, S.M., Sustainable neighborhoods in Arab world; A path towards sustainability. The Academic Research Community Publication, 3(1), 2019. DOI: 10.21625/archive.v3i1.437.

[37] Dessouky, N., Promoting a Culture of Sustainability in the Sustainable City: Identifying and Adapting Best Practices, 2018.

[38] Sharjah Sustainable City, Sharjah Sustainable City: Sharjah's first green smart city, 2020.

[39] Sharjah Sustainable City, 2019.

[40] Saundalkar, J., Shurooq and Diamond Developers announce \$544mn Sharjah Sustainable City. ME Construction News, 2019.

https://meconstructionnews.com/34053/shurooq-and-diamond-developers-announce544mn-sharjah-sustainable-city.

[41] Sharjah Sustainable City, Sharjah Sustainable City: Live a better today for a happier tomorrow, 2019.

[42] UAE off plan Properties, Properties for sale in Sharjah Sustainable City| List of off plan projects in SSC. https://dxboffplan.com/development/sharjah-sustainable-city/. Accessed on: 25 Jul. 2020. 